\title{
Axon reflex-mediated vasodilation is reduced in proportion to disease severity in TTR-FAP
}

Irène Calero-Romero, MD, Marc R. Suter, MD, Bernard Waeber, MD, Francois Feihl, MD,* and Thierry Kuntzer, MD*

Neurol Genet 2018;4:e251. doi:10.1212/NXG.0000000000000251
Correspondence

Dr. Kuntzer

thierry.kuntzer@chuv.ch

\section{Abstract}

\section{Objective}

To evaluate the area of the vascular flare in familial amyloid polyneuropathy (FAP).

\section{Methods}

Healthy controls and patients with genetically confirmed FAP were prospectively examined, on the upper and lower limbs, for thermal sensitivity (Medoc TSA-II thermal analyzer) and for axon reflex-mediated flare. The latter was induced by iontophoresis of histamine on the forearm and leg on 2 different visits. We used laser Doppler imaging (LDI) to measure the flare area (LDIflare).

\section{Results}

Six patients had FAP of variable severity; 1 had generalized analgesia secondary to leprosy (used as a positive control). The median Neurological Impairment Score-Lower Limbs (NIS-LLs) was $6(0-27)$. The warmth detection thresholds in the feet were higher in patients (median $43^{\circ}$, interquartile range $\left.39.0^{\circ}-47.6^{\circ}\right)$ compared with controls $\left(37.4^{\circ}, 35.3^{\circ}-39.2^{\circ}\right)$, indicating small fiber impairment. On the leg, LDIflare was smaller in the patients on 2 consecutive visits (controls: median 13.0 and $13.3 \mathrm{~cm}^{2}$, IQR 9.7-22.8 and 8.3-16.9; patients 6.9 and $8.0 \mathrm{~cm}^{2}$, $2.6-10.8$ and 6.4-12.1; $p=0.011$ ). LDIflare on the leg was correlated with NIS-LL (Spearman rank correlation $0.73, p=0.09$ on the first visit; Spearman rank correlation $0.85, p=0.03$ on the second visit).

\section{Conclusions}

Our study underscores that histamine-induced axon reflex-mediated vascular flare on the leg is reduced in proportion to disease severity in patients with FAP.

\section{*Co-senior last authors.}

From the Division of Clinical Pathophysiology (I.C.-R., B.W., F.F.), Department of Anaesthesiology, Pain Centre (M.R.S.), and Nerve-Muscle Unit, Neurology Service, Department of Clinical Neurosciences (T.K.), Lausanne University Hospital (CHUV), University of Lausanne, Switzerland.

Funding information and disclosures are provided at the end of the article. Full disclosure form information provided by the authors is available with the full text of this article at Neurology.org/NG.

The Article Processing Charge was funded by the authors.

This is an open access article distributed under the terms of the Creative Commons Attribution-NonCommercial-NoDerivatives License 4.0 (CC BY-NC-ND), which permits downloading and sharing the work provided it is properly cited. The work cannot be changed in any way or used commercially without permission from the journal. 


\section{Glossary}

ATTR = amyloid transthyretin; AUC = area under the curve; FAP = familial amyloid polyneuropathy; LDI = laser Doppler imaging; NIS-LL = Neurological Impairment Score-Lower Limbs; NSS = Neurological Symptom Score; PND = polyneuropathy disability; $\mathbf{Q S T}=$ quantitative sensitivity testing; $\mathbf{R O C}=$ receiver operating characteristic; $\mathbf{S k B F}=$ skin blood flow; TTR = transthyretin.

Familial amyloid polyneuropathies (FAPs) are a group of lifethreatening multisystem disorders transmitted as an autosomal dominant trait. Nerve lesions are induced by deposits of amyloid fibrils most commonly due to a transthyretin (TTR) gene mutation. The most frequently identified cause is the TTR Val30Met mutation. ${ }^{1,2}$ TTR-FAP typically causes early length-dependent small fiber polyneuropathy with alteration of temperature and pain sensations including neuropathic pain. This neurologic deficit typically points to involvement of unmyelinated and small myelinated fibers. ${ }^{2,3}$ Diagnosis of C-fiber impairment is challenging; however, the axon reflex can be assessed by objective approaches. ${ }^{4,5}$ The axon reflex is a physiologic phenomenon caused by the excitation of dermal C-fibers. Nerve impulses invade peripheral branches antidromically causing vascular dilatation, the so-called axon reflex flare reaction. ${ }^{4}$ For a long time, this flare reaction was considered unreliable as a clinical tool, making thermotesting the only recognized biomarker despite its subjectivity. ${ }^{1}$ However, recent studies using laser Doppler imaging (LDI) have demonstrated a correlation between the reduced flare size in small fiber neuropathies ${ }^{6}$ and nerve fiber density in skin biopsies, which is also reduced. ${ }^{5,7}$

Our aims were to establish (1) whether the surface area of neurogenic flare triggered by a standard stimulus could be reliably and reproducibly measured by LDI in healthy controls and patients with TTR-FAP, (2) whether this method could discriminate between the 2 groups of participants, and (3) whether the surface area of the flare in patients was reduced in proportion to TTR-FAP disease severity.

\section{Methods}

\section{Standard protocol approvals, registrations, and patient consents}

This project was approved by the Swiss Ethics Committee on research involving humans. All participants provided written informed consent.

\section{Participants}

Seven patients and 10 healthy controls were recruited prospectively for this study between spring and fall 2015. All controls were examined to ascertain their good health status including absence of skin disorders.

Patients were recruited from our own registry based on 2 inclusion criteria: the presence of neuropathic symptoms (small fiber with or without large fiber involvement) and an amyloid TTR (ATTR) mutation confirmed genetically. Patients with liver transplantation could be included. All patients underwent systematic interview and examination by the same neurologist (T.K.) and had a thorough laboratory and imaging workup. Clinical symptoms were assessed by the Neurological Symptom Score (NSS) that includes motor, sensory, and autonomic items. ${ }^{8}$ The examination performed in a temperature-controlled room included testing muscle strength, tendon reflexes, and sensory function testing including light touch, pinprick, vibration, joint position sense, and thermal sensation to calculate the Neurological Impairment Score-Lower Limbs (NIS-LLs). ${ }^{9}$ ATTR patients were classified according to the Clinical Staging of TTR-FAP, the PolyNeuropathy Disability (PND) score, and the Portuguese severity classification of TTR-FAP. ${ }^{1}$

\section{Investigation techniques}

The included patients underwent standard electrophysiologic recordings of median, sural, and fibular nerve conduction on both sides. Nerve conduction studies were considered abnormal if either nerve conduction velocity or amplitude of the sensory nerve action potentials or compound motor action potentials were abnormal (normal values from our department were used).

\section{Quantitative sensitivity testing}

Thermotesting was performed in a temperature-controlled room using a warm and cold perception threshold TSA-II NeuroSensory Analyzer (Medoc Advanced Medical Systems, Durham, NC). The established method of limits algorithm as reported from the German Research Network on Neuropathic Pain was also used. ${ }^{10}$ In short, a thermode of $9 \mathrm{~cm}^{2}$ was attached to the skin over the dorsum of the hand and foot bilaterally, and temperature ramps of $1^{\circ} \mathrm{C} / \mathrm{s}$ were applied starting from $32^{\circ} \mathrm{C}$. Participants were asked to press a button when they felt a cold or warm sensation. The investigator memorized instructions so that she could present them in a uniform fashion to each participant.

\section{Laser Doppler imaging}

The spatial distribution of skin blood flow (SkBF) was recorded with a LDI (software version 5.01; Moor Instruments, Axminster, United Kingdom) using a scanning laser beam at a wavelength of $633 \mathrm{~nm}$, as previously described. ${ }^{11,12}$

\section{Histamine induced axon reflex}

LDI was used to quantitate the flare response induced by the iontophoresis of histamine (LDIflare). This response is neurologically mediated as it is blocked by surface anesthesia, as 
previously shown, ${ }^{13}$ and verified by us in preliminary experiments in healthy controls (data not shown).

\section{Methodological details}

A $3.5 \times 4.5 \mathrm{~cm}$ zone of skin devoid of visible superficial veins was chosen on the volar face of the forearm, or on the lateral side of the calf, from which a baseline LDI scan was obtained. A ring-shaped chamber made of rubber, with an internal diameter of $0.8 \mathrm{~mm}$ fitted with a copper electrode, was then fixed to the center of the zone (using double-sided tape) and filled to the rim with $1 \%$ histamine in deionized water. A reference ECG electrode was placed similarly, nearby. Both electrodes were connected to a current source (MIC-1e iontophoresis controller; Moor Instruments). A direct current of either 20 or $100 \mu \mathrm{A}$ was applied for 60 seconds. As histamine in solution is negatively charged, the iontophoresis chamber was on the positive end of the controller. Once current delivery was terminated, the chamber was removed, the skin dried, and the area directly exposed to the histamine solution was masked with a circular piece of opaque tape. Five consecutive LDI scans of the zone were then acquired at a frequency of one every 2 minutes. For each of them, the spatial extension of SkBF increase (flare area) was determined. The maximal flare area expressed in $\mathrm{cm}^{2}$ was considered as quantification of the axon reflex within the probed skin zone. Each recorded image consisted of approximately 20,000 pixels, each with an attached flux value. Within the post-iontophoresis scans, any pixel whose value exceeded a specific threshold was considered part of the flare area. The chosen threshold was the 99th percentile of all pixel values in the baseline image.

Because of its potential confounding effect, surface temperature within the chosen skin zone was systematically recorded with a thermocouple in the minute before iontophoresis. Heat-conducting paste was used to ensure proper thermal contact between the skin and the thermocouple.

\section{Protocol}

Each participant was examined during 3 successive visits separated by at least 3 days. Visits 1 and 2 were for recording the histamine flare at various locations, whereas quantitative sensitivity testing (QST) was performed on visit 3. The same investigator (the first author, I.C.-R.) performed all examinations between 8 and $12 \mathrm{AM}$, in a quiet temperaturecontrolled room $\left(22^{\circ} \mathrm{C}-24^{\circ} \mathrm{C}\right)$, with the participant lying comfortably on a hospital bed.

On visit 1, 4 pairs of skin zones were chosen, 1 on each forearm and 1 on each calf. Zones within each pair were at least $10 \mathrm{~cm}$ apart and were both allocated to receive histamine iontophoresis, with a current intensity of $20 \mu \mathrm{A}$ on 1 zone and $100 \mu \mathrm{A}$ on the other. On the upper and lower limbs, treated zones at both intensities were placed as symmetrically as possible and their location recorded on transparent film. A total of 8 histamine flares were thus recorded: 2 intensities on each of the 4 limbs. The order of rotation between limbs and for intensities on limbs was randomized. The whole procedure including setup, acquisition of baseline, iontophoresis, acquisition of postiontophoresis images required approximately 30 minutes, making for a total visit duration of 4 hours.

For each participant, visit 1 protocol was repeated identically on visit 2 , so as to assess the intraindividual variability. In particular, the recording zones were repositioned as exactly as possible at the same spot (made possible by the aforementioned recording on transparent film), with intensity allocation and rotation order identical to those of visit 1 .

\section{Data analysis}

Histamine flare and local skin temperature data were evaluated statistically with mixed-model analysis of variance, using the xtmixed procedure in Stata version 12 (Stata Corp LP). Responses obtained at the same iontophoretic current intensity at symmetrical locations were considered as replicates, and data from the upper and lower limbs were analyzed separately. Thus, the model comprised participant group (control or patient), current intensity ( 20 or $100 \mu \mathrm{A})$, visit number ( 1 or 2 ), and all 2- and 3-way interactions. In a second step, interactions with $p$ values $>0.1$ were removed. The $p$ values reported in the results are from this more parsimonious model.

The same general method was used to evaluate each of the 4 outcome measures generated by QST testing (detection and pain thresholds for warm and cold stimulations). In this case, the model was simpler because there was only 1 visit and that stimulus intensity was not a factor.

The relationship between histamine flare and clinical severity score (NIS-LL) was assessed with Spearman rank correlation coefficient. Finally, we compared the ability of histamine flare and QST data to discriminate between groups, using receiver operating characteristic (ROC) curve analysis. Logistic regression was performed with group membership as the outcome variable and either histamine flare at a specific intensity or specific QST responses as predictors (procedure logistic, followed by the lroc command in Stata). The area under the ROC curve (AUC) was calculated. The AUC can range from 0.5 to 1 , with the former value indicating no, and the latter, perfect discriminating ability.

\section{Results}

We recruited 6 patients, all women, with FAP of variable severity (table 1). All had a confirmed mutation in the TTR gene: Val30Met in 5 cases and Glu89Lys in one. As a positive control (table 1), we included a seventh male patient with generalized analgesia secondary to lepromatous leprosy. His individual data indicated below is excluded from all statistical calculations (see Patients' characteristics). By "patient group" (or "patients"), we therefore mean only the 6 patients with FAP. Of the 10 healthy controls, 5 were women and the remaining were men. Their median age was 50 years (range 
20-64). For comparison, the median age of the 6 FAP patients was also 50 years (range 37-58).

\section{Patients' characteristics}

All underwent extensive blood workup and imaging studies and excluded metabolic, immunologic, or infectious causes of small fiber neuropathy, in particular, diabetes, neurodegenerative diseases, and paraneoplastic syndromes.

Table 1 contains a detailed description of our patients. Patients were overweight with a median body mass index of $29.4 \mathrm{~kg} / \mathrm{m}^{2}$ (range 28.5-31.9) corresponding to the range of the controls (mean $29.8 \mathrm{~kg} / \mathrm{m}^{2}: 27.5-31.7$ ). The median duration of FAP was 12 years. Echocardiography was abnormal in P04 and P06 only. Nerve conduction studies revealed carpal tunnel syndrome in 4 patients (P01, P02, P04, and P06) and reduced or absent sural/fibular nerve potentials in 3 (P01, P03, and P04). Four patients had undergone liver transplantation. Among them, the patient with the GLu89Lys mutation (P04) also had a heart transplant, as published previously. ${ }^{14}$ Clinical manifestations were scored according to NSS, a well-disseminated score used to quantify symptoms in patients with neuropathies of various causes, and all had neuropathic symptoms; neurologic examination was quantified using scores dedicated to patients with FAP (the so-called NIS-LL). These scores were correlated with clinical FAP severity and with signs of large nerve fiber neuropathy on examination. As it can be deduced from NSS and NIS-LL data, patients P02, P05, and P06 were mildly affected having only a small nerve fiber neuropathy. Patients P01, P03, and P04 had the highest NSS and NIS-LL scores and were the most affected having concomitant small and large nerve fiber neuropathy. These 3 patients had abnormal sensory nerve action potentials. Concerning the clinical staging of the disease, all 6 patients were at stage I of the Clinical Staging of TTR-FAP, a stage used to start therapeutic options in the clinical setting. Patients were heterogeneously distributed according to the PND score (median 1 of 4 ) or to the Portuguese severity classification of TTR-FAP (median 2 of 6 ). The patient with leprosy was the most severely affected.

\section{Thermotesting}

Thermotesting results from the hands and feet in the 2 groups are shown in table 2. Patients differed statistically from controls on the hands and on the feet, with respect to detection threshold for both warm and cold. Differences were more marked on the feet, however, indicating length-dependent small fiber impairment in the patients.

\section{Histamine flare}

Figure 1 shows the area of the flare induced by the 2 iontophoretic doses of histamine, measured by LDI on the forearms and legs on visits 1 and 2, for each study participant. Regarding statistical analysis, the only interaction terms that came out marginally significant when fitting the full model was between the group and the iontophoretic dose $(p=0.07$, below the predefined level of 0.1 , see Methods). Therefore, the statistical 
Table 2 Results of QST in the control and patient groups

\begin{tabular}{|c|c|c|c|c|c|}
\hline & \multicolumn{2}{|l|}{ Controls } & \multicolumn{2}{|l|}{ Patients } & \multirow{2}{*}{$\begin{array}{l}p \\
\text { Value }\end{array}$} \\
\hline & Median & IQR & Median & IQR & \\
\hline \multicolumn{6}{|l|}{ Hand } \\
\hline $\begin{array}{l}\text { Detection, } \\
\text { warm }\end{array}$ & 34.4 & $33.4-36.1$ & 36.1 & $35.1-40.5$ & 0.053 \\
\hline $\begin{array}{l}\text { Detection, } \\
\text { cold }\end{array}$ & 31.2 & $30.2-31.3$ & 30.4 & $28.8-30.7$ & 0.025 \\
\hline Pain, warm & 44.9 & $42.9-47.7$ & 43.5 & $40.1-48.2$ & ns \\
\hline Pain, cold & 14.2 & $7.5-20.2$ & 8.6 & $3.2-10.5$ & ns \\
\hline \multicolumn{6}{|l|}{ Foot } \\
\hline $\begin{array}{l}\text { Detection, } \\
\text { warm }\end{array}$ & 37.4 & $35.3-39.2$ & 43.0 & $39.0-47.6$ & 0.003 \\
\hline $\begin{array}{l}\text { Detection, } \\
\text { cold }\end{array}$ & 28.5 & $27.3-29.8$ & 26.3 & $4.0-28.3$ & 0.040 \\
\hline Pain, warm & 45.7 & $44.6-46.6$ & 48.6 & $46.5-50.0$ & ns \\
\hline Pain, cold & 7.7 & $2.7-21.9$ & 2.1 & $0.0-8.8$ & ns \\
\hline
\end{tabular}

Abbreviations: IQR = interquartile range; $\mathrm{QST}$ = quantitative sensitivity testing.

Measurements made on the left and right sides were considered as replicates: averaged at the individual level and then summarized for the 2 groups as indicated. All values are absolute temperature in ${ }^{\circ} \mathrm{C}$. $p$ Values refer to the comparison of patients with controls.

results reported here are from a model comprising simple main effects and this specific interaction. The dose-response effect was clearly visible and statistically highly significant on both visits $(p<0.001)$. On the forearm, the histamine flare area did not differ, at either dose, between the 2 groups $(p=0.30)$. By contrast, on the leg, this response was less intense in patients, at least for the higher dose of histamine, on both visit 1 (controls: median $13.0 \mathrm{~cm}^{2}$, interquartile range $[\mathrm{IQR}] 9.7-22.8$; patients: median $6.9 \mathrm{~cm}^{2}$, IQR 2.6-10.8; $p=0.011$ vs controls) and visit 2 (controls: median $13.3 \mathrm{~cm}^{2}$, IQR 8.3-16.9; patients: median $8.0 \mathrm{~cm}^{2}$, IQR 6.4-12.1; $\left.p=0.011\right)$.

The measurements of local skin temperature ( $T$ _skin) performed before each iontophoresis are detailed in table e-1 (links.lww.com/NXG/A61). On average, T_skin appeared slightly but significantly lower in patients compared with controls. Statistical analysis was repeated while adding this possible confounder to the model with essentially identical results: the dose-response effect remained $(p<0.001)$; the difference in the flare area between patients and controls was still significant on the leg at a current dose of $100 \mu \mathrm{A}(p=$ $0.019)$, but not on the forearm at either dose $(p=0.47)$.

In patients, the area of histamine flare on the leg was inversely correlated with the clinical status, as shown in figure 2. P01, P03, and P04 were the most affected patients, having concomitant small and large nerve fiber neuropathy and abnormal sensory nerve action potentials. This correlation held up whether values for the histamine flare area were taken from visit 1 (Spearman $\left.\mathrm{R}^{2} 0.73, p=0.09\right)$ or visit $2\left(\mathrm{R}^{2} 0.85, p=\right.$ 0.03 ). Indeed, flare areas on both visits were nearly identical in 4 of the 6 patients, although further apart in the other 2 .

The intraindividual variation in the histamine flare area from visit 1 to visit 2 is shown more completely in figure 3 (which for the sake of brevity only displays data obtained from the

Figure 1 Histamine flare in patients and controls
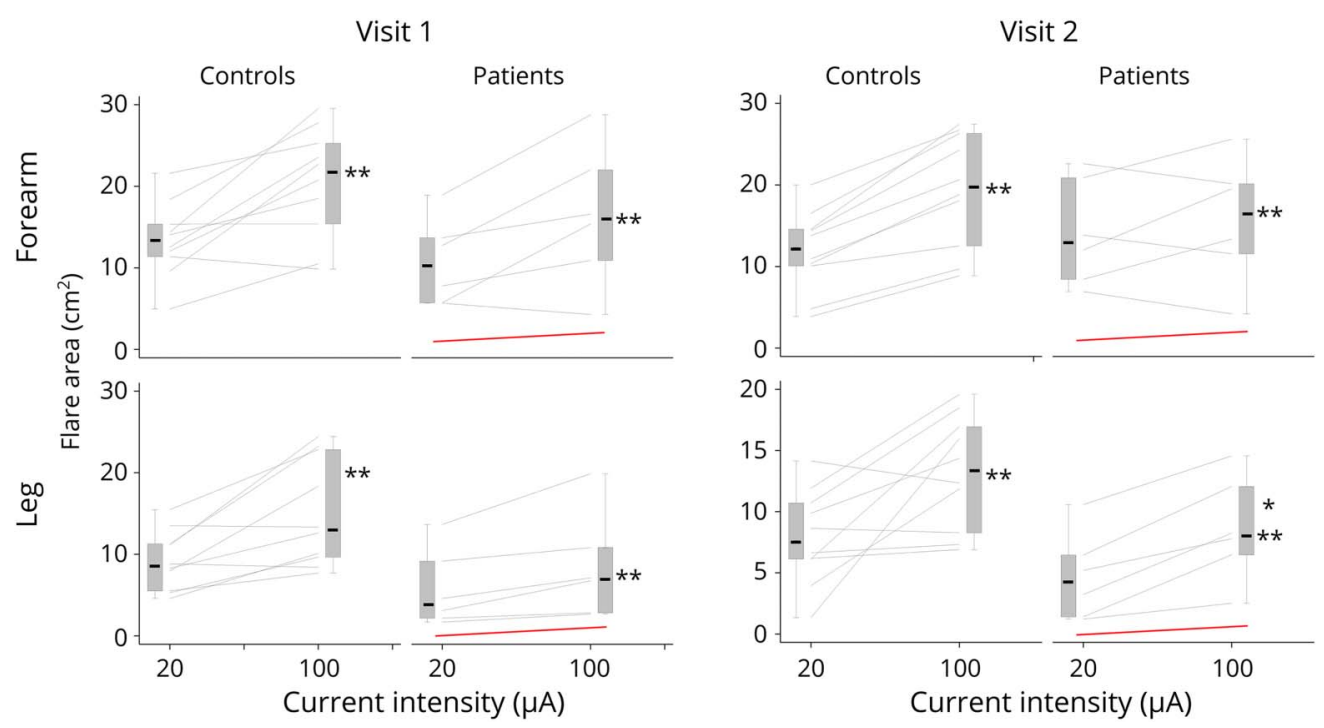

Measurements made on the left and right sides of the same person were considered replicates, averaged and plotted as shown, for each study participant. The box plots indicate the median, interquartile range, and extreme values. ${ }^{\star} p<0.05$ patients vs controls. ${ }^{* *} p<0.01$ iontophoretic dose of 100 vs $20 \mu \mathrm{A}$. The red line corresponds to the positive control patient (table 1). 


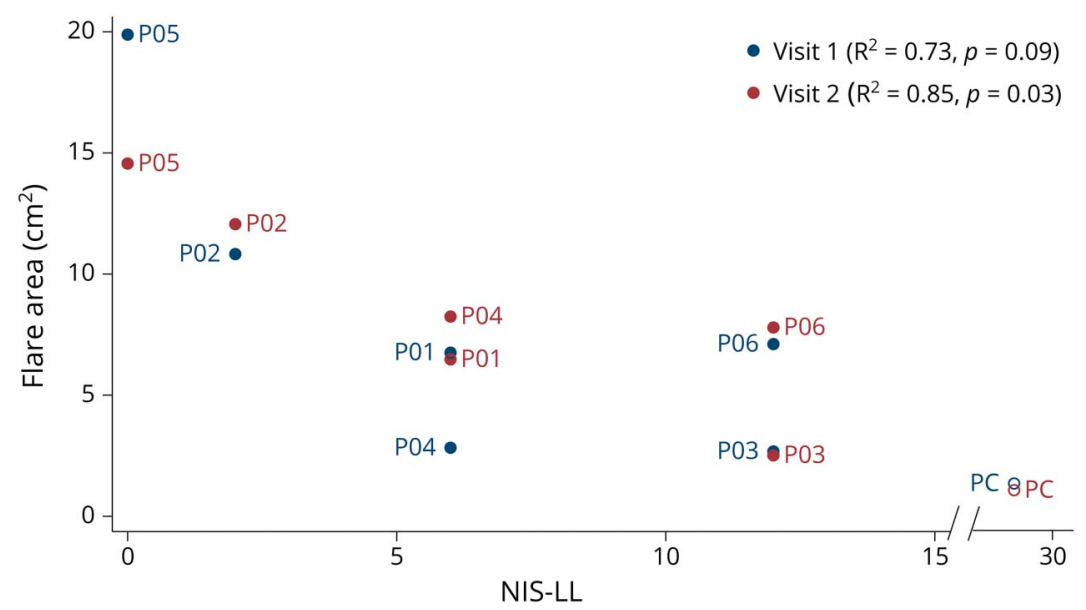

$\mathrm{R}^{2}$ : Spearman rank correlation coefficient. Data points labeled according to the patient ID (table 1). NIS-LL = Neurological Impairment Score-Lower Limbs; PC = positive control. highest iontophoretic current dose) in the form of Bland and Altman plots. These plots reveal negligible bias (none of which reached statistical significance), but relatively wide limits of agreement.

As evaluated from ROC curve analysis (figure 4), the ability of histamine flare to discriminate between patients and controls was similar on visit 1 (AUC 0.81) and visit 2 (0.77). Furthermore, the performances of histamine flare and QST testing were comparable (AUC for QST testing, 0.78).

\section{Discussion}

Based on our previous experience in quantifying spatial distribution of SkBF with $\mathrm{LDI},{ }^{12,15,16}$ we present here the

Figure 3 Bland and Altman plots of histamine flare areas on the leg, recorded on visits 1 and 2

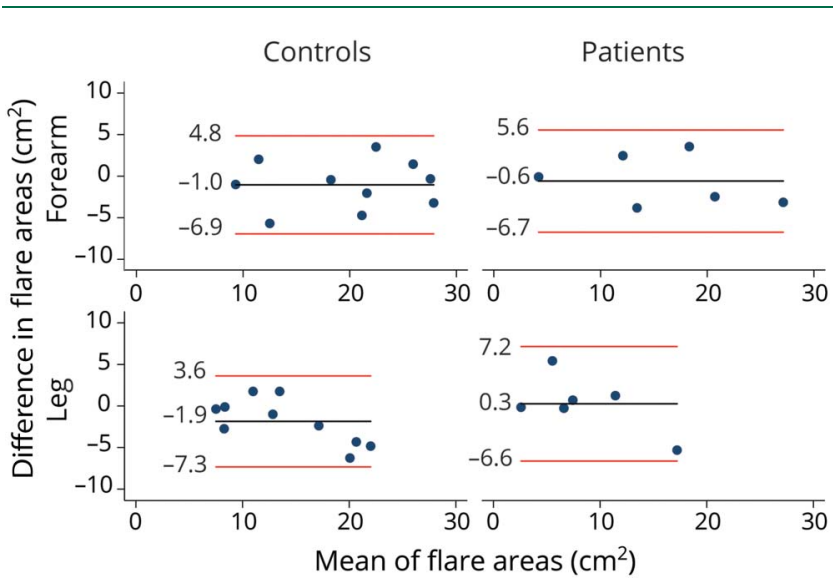

Data from flares induced with the $100 \mu \mathrm{A}$ iontophoretic current on the leg. Full horizontal lines: average difference across participants (bias). Dashed lines: limits of agreement. Numerical values for bias and limits of agreement shown on each plot, expressed in $\mathrm{cm}^{2}$. findings from a prospective study comparing LDIflare in patients with FAP and controls. Our results indicate that axon reflex-mediated neurogenic cutaneous vasodilation in response to histamine measured by LDI (1) is easily elicited in both groups of participants, (2) is only moderately reproducible at the intraindividual level, (3) despite this latter limitation appears clearly reduced in patients according to a length-dependent pattern, and (4) shows an ability similar to QST testing for discriminating between patients and controls.

The reproducibility of our results was assessed by intraindividual variation in the histamine flare area from visit 1 to visit 2 (figure 3), revealing negligible bias with no statistical significance, but relatively wide limits of agreement. This result is in accordance with what is already known in LDIflare studies. ${ }^{17,18}$

We showed a length-dependent pattern in our patients with FAP: the histamine flare response on the leg was less intense in patients than in controls, at least for the higher dose of histamine, whereas it did not differ, at either dose, between the 2 groups on the forearm. This result is consistent with QST testing: in patients, the detection thresholds for cold and warm were clearly more abnormal in the feet compared with the hands (table 2). This is in line with observations reported by others in patients with FAP despite the subjectivity of QST testing. ${ }^{1}$

Among the tests for small fiber function, ${ }^{3}$ QST is considered a gold standard tool. ${ }^{1,19}$ In terms of ability to discriminate between patients and healthy controls, LDIflare has been variously reported as inferior to QST in diabetic neuropathies ${ }^{20}$ or equivalent in neuropathies of mixed etiologies. ${ }^{21}$ In keeping with this latter study, ROC curve analysis in our case showed a similar performance of histamine flare and QST (figure 4). The discrepancy between studies could reflect methodological differences. Alternatively, it may be related to 

(QST)
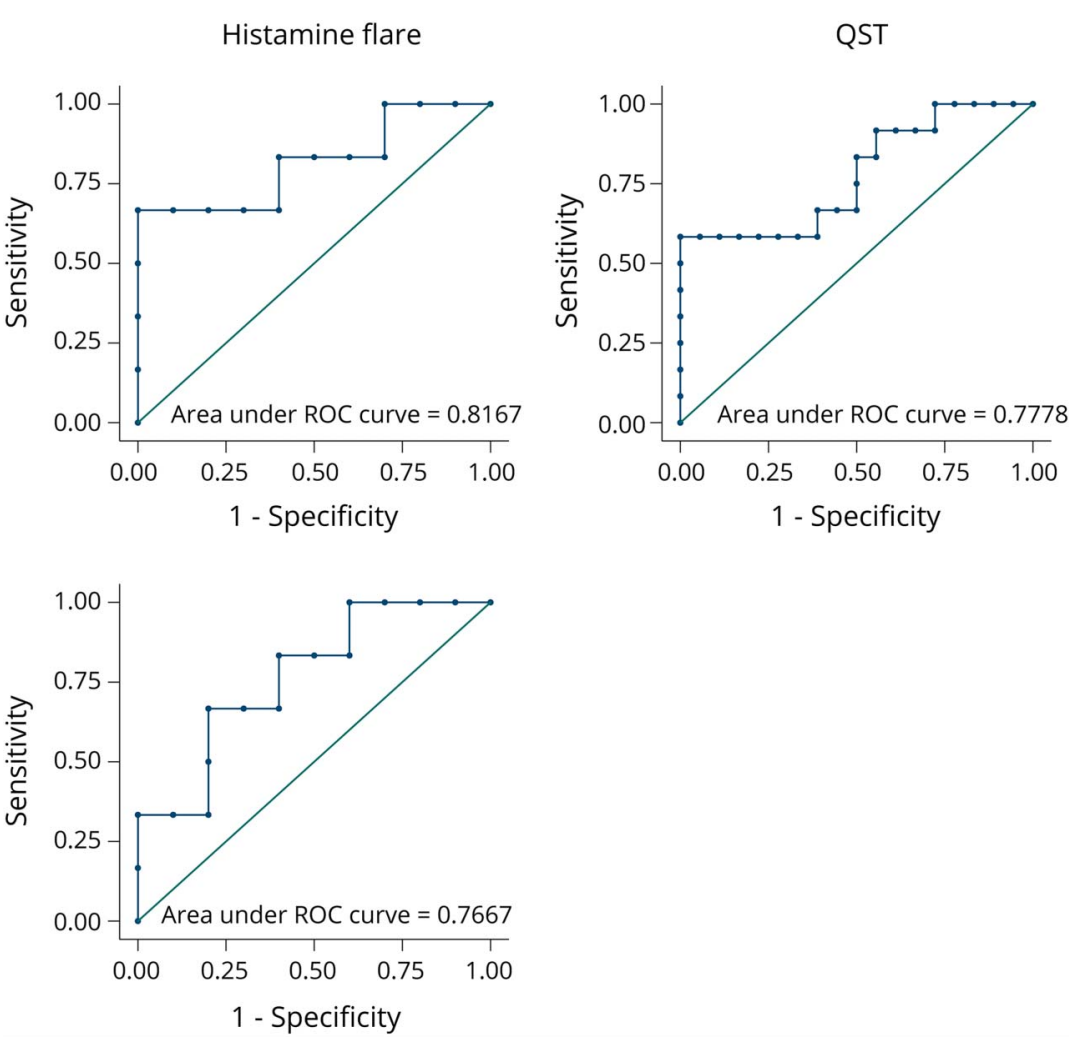

Receiver operating characteristic (ROC) curves derived from logistic regression analysis, with group membership as the dependent variable. Predictors in the model were those on which the groups differed statistically, i.e., histamine flare area on the legs at a current intensity of $100 \mu \mathrm{A}$ (figure 2) or detection threshold for warm and cold on the hands and feet (table 2).

different sample sizes and case mix. Our patients had peripheral neuropathies of homogeneous etiology. However, their small number precludes any meaningful calculation of cutoff points for estimating the respective sensitivities and specificities of LDIflare and QST. A larger study is required to that effect, keeping in mind that the ultimate clinical usefulness of these tests would depend on their negative/positive predictive values. The latter, in addition to specificity and sensitivity, are in turn determined by the prevalence of the condition under investigation.

An important result of our study is the correlation between the LDIflare area and NIS-LL, a score recently found to be a valid and reliable measure of TTR-FAP severity. ${ }^{17}$ This a new correlation being up to now only demonstrated by nerve biomarkers obtained from skin biopsies. ${ }^{22}$ This is valid for our patients independently of clinical small or large nerve fiber involvement or absent/reduced sensory nerve action potentials on nerve conduction studies.

The current study has limitations. Considering FAP heterogeneity, ${ }^{1}$ our small patient sample may not be representative. However, our data provide a rationale for the use of reflexmediated neurogenic cutaneous vasodilatation in response to histamine in a larger scale. This reflex measured by LDI is an objective and quantitative measure that can potentially serve as a useful biomarker, assessing TTR-FAP severity in epidemiologic surveys and therapeutic trials, even at an early disease stage.

\section{Author contributions}

I. Calero-Romero: acquisition of data, analysis or interpretation of data, and revision of the manuscript. M. R. Suter: analysis of data and revision of the manuscript. B. Waeber: revision of the manuscript and study supervision. F. Feihl: study concept and design, acquisition of data, study supervision, analysis and interpretation of data, statistical analysis, and drafting and revision of the manuscript. T. Kuntzer: study concept or design, acquisition of data, study supervision, analysis and interpretation of data, and drafting and revision of the manuscript.

\section{Acknowledgment}

The authors are grateful to all patients, relatives, and other controls for accepting to participate in the study. They thank Dr. Melanie Price and Dr. Pinelopi Tsouni for critical reading of the manuscript.

\section{Study funding}

No targeted funding reported.

\section{Disclosure}

I. Calero-Romero reports no disclosures. M.R. Suter has served on the scientific advisory boards of Indivior and Pfizer; 
serves on the editorial board of Revue Médicale Suisse; and has received research support from Pfizer, IASP, and the European Society of Anaesthesiology. B. Waeber and F. Feihl report no disclosures. T. Kuntzer has served on the scientific advisory board of the French Peripheral Society and has received funding for travel/speaker honoraria from CSL Behring. Full disclosure form information provided by the authors is available with the full text of this article at Neurology. org/NG.

Received December 29, 2017. Accepted in final form May 15, 2018.

\section{References}

1. Ando Y, Coelho T, Berk JL, et al. Guideline of transthyretin-related hereditary amyloidosis for clinicians. Orphanet J Rare Dis 2013;8:31.

2. Plante-Bordeneuve V, Said G. Familial amyloid polyneuropathy. Lancet Neurol 2011; 10:1086-1097.

3. Hoeijmakers JG, Faber CG, Lauria G, Merkies IS, Waxman SG. Small-fibre neuropathies-advances in diagnosis, pathophysiology and management. Nat Rev Neurol 2012;8:369-379.

4. Chiu IM, von Hehn CA, Woolf CJ. Neurogenic inflammation and the peripheral nervous system in host defense and immunopathology. Nat Neurosci 2012;15: 1063-1067.

5. Bickel A, Heyer G, Senger C, et al. C-fiber axon reflex flare size correlates with epidermal nerve fiber density in human skin biopsies. J Peripher Nerv Syst 2009;14: 294-299.

6. Kubasch ML, Kubasch AS, Torres Pacheco J, et al. Laser doppler assessment of vasomotor axon reflex responsiveness to evaluate neurovascular function. Front Neurol 2017;8:370.

7. Namer B, Pfeffer S, Handwerker HO, Schmelz M, Bickel A. Axon reflex flare and quantitative sudomotor axon reflex contribute in the diagnosis of small fiber neuropathy. Muscle Nerve 2013;47:357-363.
8. Dyck PJ, Hughes RAC, O'Brien PC. Quantitating overall neuropathic symptoms, impairments, and outcomes. In: Peripheral Neuropathy, 4th ed: Elsevier; 2005: 1031-1051.

9. Bril V. NIS-LL: the primary measurement scale for clinical trial endpoints in diabetic peripheral neuropathy. Eur Neurol 1999;41(suppl 1):8-13.

10. Magerl W, Krumova EK, Baron R, Tolle T, Treede RD, Maier C. Reference data for quantitative sensory testing (QST): refined stratification for age and a novel method for statistical comparison of group data. Pain 2010;151:598-605.

11. Golay S, Haeberli C, Delachaux A, et al. Local heating of human skin causes hyperemia without mediation by muscarinic cholinergic receptors or prostanoids. J Appl Physiol 2004;97:1781-1786.

12. Frantz J, Engelberger RP, Liaudet L, Mazzolai L, Waeber B, Feihl F. Desensitization of thermal hyperemia in the skin is reproducible. Microcirculation 2012;19:78-85.

13. Harper EI, Beck JS, Spence VA. Effect of topically applied local anaesthesia on histamine flare in man measured by laser doppler velocimetry. Agents Actions 1989;28: 192-197.

14. Niederhauser J, Lobrinus JA, Ochsner F, et al. Successful heart and liver transplantation in a Swiss patient with Glu89Lys transthyretin amyloidosis. Transplantation 2011;91:e40-e42.

15. Engelberger RP, Pittet YK, Henry H, et al. Acute endotoxemia inhibits microvascular nitric oxide-dependent vasodilation in humans. Shock 2011;35:28-34

16. Ciplak M, Pasche A, Heim A, et al. The vasodilatory response of skin microcirculation to local heating is subject to desensitization. Microcirculation 2009;16:265-275.

17. Vas PR, Rayman G. The rate of decline in small fibre function assessed using axon reflex-mediated neurogenic vasodilatation and the importance of age related centile values to improve the detection of clinical neuropathy. PLoS One 2013;8:e69920.

18. Green AQ, Krishnan ST, Rayman G. C-fiber function assessed by the laser doppler imager flare technique and acetylcholine iontophoresis. Muscle Nerve 2009;40:985-991.

19. Devigili G, Tugnoli V, Penza P, et al. The diagnostic criteria for small fibre neuropathy: from symptoms to neuropathology. Brain 2008;131:1912-1925.

20. Gibbons CH, Freeman R, Veves A. Diabetic neuropathy: a cross-sectional study of the relationships among tests of neurophysiology. Diabetes Care 2010;33:2629-2634.

21. Abraham A, Alabdali M, Alsulaiman A, et al. Laser doppler flare imaging and quan titative thermal thresholds testing performance in small and mixed fiber neuropathies. PLoS One 2016;11:e0165731.

22. Ebenezer GJ, Liu Y, Judge DP, et al. Cutaneous nerve biomarkers in transthyretin familial amyloid polyneuropathy. Ann Neurol 2017;82:44-56. 


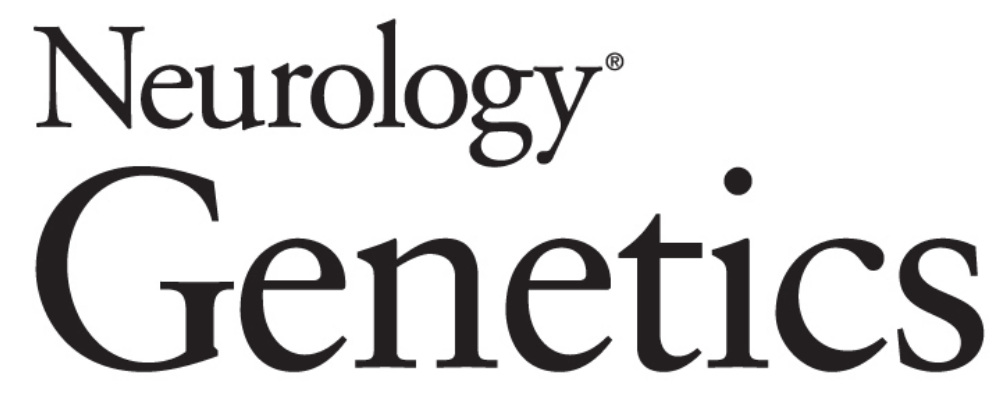

\section{Axon reflex-mediated vasodilation is reduced in proportion to disease severity in TTR-FAP \\ Irène Calero-Romero, Marc R. Suter, Bernard Waeber, et al. \\ Neurol Genet 2018;4; \\ DOI 10.1212/NXG.0000000000000251}

This information is current as of August 3, 2018

\section{Updated Information \& Services}

References

Subspecialty Collections

Permissions \& Licensing

Reprints including high resolution figures, can be found at: http://ng.neurology.org/content/4/4/e251.full.html

This article cites 21 articles, 1 of which you can access for free at: http://ng.neurology.org/content/4/4/e251.full.html\#\#ref-list-1

This article, along with others on similar topics, appears in the following collection(s):

All clinical neurophysiology

http://ng.neurology.org//cgi/collection/all_clinical_neurophysiology All Genetics

http://ng.neurology.org//cgi/collection/all_genetics

Autonomic diseases

http://ng.neurology.org//cgi/collection/autonomic_diseases

Peripheral neuropathy

http://ng.neurology.org//cgi/collection/peripheral_neuropathy

Information about reproducing this article in parts (figures,tables) or in its entirety can be found online at:

http://ng.neurology.org/misc/about.xhtml\#permissions

Information about ordering reprints can be found online:

http://ng.neurology.org/misc/addir.xhtml\#reprintsus

Neurol Genet is an official journal of the American Academy of Neurology. Published since April 2015, it is an open-access, online-only, continuous publication journal. Copyright Copyright $\odot 2018$ The Author(s). Published by Wolters Kluwer Health, Inc. on behalf of the American Academy of Neurology.. All rights reserved. Online ISSN: 2376-7839.

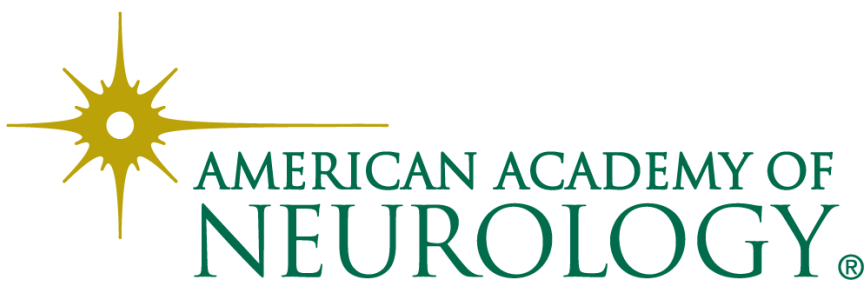

